\title{
Sequential Application of Soil Vapor Extraction and Bioremediation Processes for the Remediation of Ethylbenzene-Contaminated Soils
}

\author{
António Alves Soares \& Maria Teresa Pinho \& \\ José Tomás Albergaria \& Valentina Domingues \& \\ Maria da Conceição M. Alvim-Ferraz \& \\ Paolo De Marco \& Cristina Delerue-Matos
}

\begin{abstract}
Soil vapor extraction (SVE) is an efficient, wellknown and widely applied soil remediation technology. However, under certain conditions it cannot achieve the defined cleanup goals, requiring further treatment, for example, through bioremediation (BR). The sequential application of these technologies is presented as a valid option but is not yet entirely studied. This work presents the study of the remediation of ethylbenzene(EB)-contaminated soils, with different soil water and natural organic matter (NOMC) contents,
\end{abstract}

using sequential SVE and BR. The obtained results allow the conclusion that: (1) SVE was sufficient to reach the cleanup goals in $63 \%$ of the experiments (all the soils with NOMC below 4\%), (2) higher NOMCs led to longer SVE remediation times, (3) BR showed to be a possible and cost-effective option when EB concentrations were lower than $335 \mathrm{mg} \mathrm{kg}_{\underline{s_{1}}}{ }^{-1}$, and (4) concentrations of EB above $438 \mathrm{mg} \mathrm{kg}_{\mathrm{so}_{\mathrm{il}}}{ }^{-1}$ showed to

be inhibitory for microbial activity.

Keywords

Ethylbenzene, Soil vapor extraction, Bioremediation, Organic matter, Water content, Remediation time

\section{Introduction}

The inadequate use, storage, and transport of petroleum products have led to innumerous cases of soil contamination. Among the compounds present in petroleum products, ethylbenzene (EB) can be highlighted. EB is essential for the production of styrene, which, in turn, is used for the fabrication of polystyrene. EB is also used as a solvent and as a constituent of asphalt, naphtha, and fuels (ATSDR 1999). According to the United States Environmental Protection Agency, EB, being a constituent of the BTEX group (benzene, toluene, EB, and xylene isomers), is one of the most common contaminants in polluted sites in the USA (USEPA 2010). To invert this situation, significant efforts have been made 
in the last decades to rehabilitate these sites. This task has been achieved through the use of several remediation technologies, including soil vapor extraction (SVE) and bioremediation (BR), two of the most often used remediation technologies in sites contaminated with hydrocarbons (USEPA 2010).

SVE is an in situ technology and is especially efficient for the remediation of soils contaminated with volatile and semi-volatile organic compounds located in the unsaturated zone of the soil. It makes use of the high volatility of the contaminants to transport them via an airflow created in the soil matrix by the induction of vacuum conditions. The contaminated airflow is removed from the soil through strategically located extraction wells (Suthersan 1999). The advantages of SVE systems are related to their relative low cost, simplicity of installation and operation, and the reduced amount of required equipment (Suthersan 1999). The SVE's efficiency is affected by factors such as soil permeability, applied vacuum, airflow rate, temperature, vapor pressure, natural organic matter content (NOMC), and soil water content (SWC) (Sepehr and Samani 1993).

NOMC is one of the most important parameters to be taken into account when SVE is used because of its impact on the adsorption phenomena which influence the mobility and availability of the contaminants in the soil matrix. Even a low amount of organic matter is sufficient to dominate the sorption processes and is responsible for most of the sorption capacity of volatile organic compounds (VOCs) (Grasso 1993). In a previous study (Alvim-Ferraz et al. 2006), it was demonstrated that the NOMC has a negative impact on SVE performed in cyclohexane-contaminated soils, leading to longer (six times) and less efficient remediations (10\% decrease). Qin et al. (2010) showed that when SVE is performed in chlorobenzene-contaminated soils with a low NOMC $(0.4 \%)$, the process is extremely efficient $(96 \%)$, but in soils with higher NOMC (4.2\%), the efficiency decreases significantly $(66 \%)$. Similar results were obtained by Sun et al. (2003) for soils contaminated with naphthalene and pyrene.

The SWC also affects the SVE's remediation time and efficiency because of its influence on the contaminant's availability and on the soil's permeability. The latter is the most important factor in the migration of VOCs through the soil (Harper et al. 1998). Soils with higher SWCs have lower porosity which hinders the movement of pumped air to certain portions of the soil, resulting in a negative effect on the remediation efficiency (Poulsen et al. 1999). This impact was also demonstrated by Alvim-Ferraz et al. (2006): longer remediation times (approximately double) with slightly lower efficiencies ( $2 \%$ decrease) were obtained for soils with higherSWCs.

These examples indicate that in certain conditions SVE can be insufficient to achieve the cleanup goals defined by land owners or imposed by law. In order to achieve these cleanup levels, complementary actions should be taken. The utilization of BR as a complementary remediation technology is a cheap and easy, but often slow, option. BR is applicable to large areas and causes less undue damage compared to other physical or chemical remediation technologies (Yang et al. 2009). BR uses microorganisms, native in many cases, to degrade and/or eliminate contaminants from the soil matrix. However, the existence of microorganisms in a contaminated site does not assure that BR is possible. To perform the remediation, the microorganisms should be able to degrade the target compounds and to tolerate environmental changes. Furthermore, the soil matrix should possess good conditions for the active microorganisms (Thomassin-Lacroix 2000). The underground soil has small amounts of microorganisms (Corseuil and Weber 1994) and, in some cases, deficient levels of nutrients (Lewis et al. 1986) which compromises the degrading conditions even further. These difficulties could be overcome through the use of two different technologies: biostimulation and bioaugmentation. Biostimulation aims to increase the microbial activity through the addition of nutrients and the enhancement of the contaminants' bioavailability. Bioaugmentation consists of the inoculation of degrading bacteria that have shown good results in terrestrial environments, accelerating the biodegradation process (Yang et al. 2009).

$\mathrm{BR}$ is also negatively influenced by several parameters such as low temperatures, low levels of nutrients and/or co-substrates, anaerobic conditions, and low bioavailability or absence of degradation potential (Romantshuck 2000). The presence of macro- and micronutrients, in certain concentrations, assures good degradability conditions for the soil's microorganisms. Jean et al. (2008) showed that an increase of the level of nutrients such as sulfate, phosphate, and ammonium chloride resulted in an enhanced bacterial growth and a better degradation of benzene, toluene, and xylene in 
soil. The lack of some nutrients can render the remediation under natural conditions inefficient (Tyagi et al. 2011).

The NOMC can also influence the bioremediation process. Soils with higher NOMCs usually house higher amounts of microorganism, which can indicate that there is a higher number of degrading agents in soil. This was observed by Soares et al. (2010) where the bioremediations performed in soils with higher NOMCs led to faster remediations.

There are still few research studies on the sequential application of SVE and BR. In a recent study performed by our group (Soares et al. 2010), the combination of SVE and BR enabled the achievement of the cleanup goals imposed by the Spanish Legislation for soils contaminated with benzene. With the use of SVE alone, the legal limits were reached in $71 \%$ of the experiments. The remaining $29 \%$ were achieved by complementary BR.

Although there are several published studies dealing with this subject, there is not enough detailed information that can be of extreme importance to field technicians that require all available information to define which remediation technology could be the most appropriate to a certain contamination case.

The present work reports the study of the utilization of SVE with BR to remediate EB-contaminated soils with different SWCs and NOMCs. The main objectives were to evaluate: (1) the SVE's efficiency and remediation time, (2) the bioremediation time, and (3) the influence of SWC and NOMC on SVE and BR.

\section{Experimental}

\subsection{Reagents}

EB (>99\%) was purchased from Merck and mineral medium (MinE-containing $\mathrm{CaCl}_{2} \cdot \mathrm{H}_{2} \mathrm{O}, \mathrm{MgSO}_{4}$, and $\left.\left(\mathrm{NH}_{4}\right)_{2} \mathrm{SO}_{4}\right)$ was prepared according to Kelly et al. (1994).

\subsection{Apparatus and Chromatography}

Both SVE and BR processes were monitored with a gas chromatograph (Shimadzu GC-2010) equipped with a flame ionization detector and a TRB 35 NF$2670(30 \mathrm{~m} \times 0.53 \mathrm{~mm} \times 3 \mu \mathrm{m})$ column. The injectors and the detectors were set at $250^{\circ} \mathrm{C}$, and the column was maintained at $200^{\circ} \mathrm{C}$ throughout the analysis. Helium at $30 \mathrm{~cm}^{3} \mathrm{~min}^{-1}$ was used as the carrier gas. Flame gases were: air $\left(400 \mathrm{~cm}^{3} \mathrm{~min}^{-1}\right)$ and hydrogen $\left(40 \mathrm{~cm}^{3} \min ^{-1}\right)$. Chromatographic data were recorded and treated using GC Solution Analysis software, version 2.30.00 (Shimadzu). The quantification of EB was performed by the external standard calibration method using eight standards within the desired concentration range $\left(0.5-40 \mathrm{gm}^{-3}\right)$. Each standard was analyzed in triplicate. The calibration curves had correlation coefficients between 0.9971 and 0.9977 .

\subsection{Soil Preparation and Characterization}

The sandy soil was collected at a depth of $3 \mathrm{~m}$ from different spots on a beach, and the humic soil was collected in a forest at a depth of $2-5 \mathrm{~cm}$. Both samples were obtained from the region around Porto, Portugal and were stored in appropriate vessels in a "noncontaminated," cool, and dry room (temperature, $\left.10 \pm 2^{\circ} \mathrm{C}\right)$.

The international standard methodologies used for the characterization of the prepared and real soils as well as the results are presented in Soares et al. (2010). The soils were identified as $\mathrm{P}_{\mathrm{a}, \mathrm{b}}$ or $\mathrm{R}_{\mathrm{a}, \mathrm{b}}$, the letters $\mathrm{P}$ and $\mathrm{R}$ indicating if the soil was prepared or real and the letters $\mathrm{a}$ and $\mathrm{b}$ indicating the contents of water and organic matter, respectively.

2.4 Remaining Contamination Level and Determination of the SVE Efficiency

The evaluation of the performance of the SVE process requires the determination of the concentration of the contaminant after remediation. This was achieved using the methodology described in Albergaria et al. (2006). Several columns containing different soils with different levels of contamination were prepared. After the establishment of equilibrium inside the columns, the concentration of the contaminant in the gas phase of the soil was determined by gas chromatography. Through data fitting, a mathematical function relating the concentration of the contaminant in the gas phase of the soil and the level of contamination in the soil was obtained. Using this mathematical equation and the measured concentration in the gas phase, it was possible to calculate the contaminant's concentration in the soil at the end of each SVE and subsequently the efficiency of the process. 


\subsection{Soil Vapor Extraction Experiments}

The SVE experiments were performed in stainless steel columns $(h 037 \mathrm{~cm}$; i.d.010 cm). The preparation of these columns consisted of four stages: (1) introduction of the soil in the column, (2) soil contamination with $\mathrm{EB}$, (3) equilibrium settling, and (4) determination of the EB concentration in the gas phase of the soil using gas chromatographic analysis. In the first stage, an adequate amount of soil was introduced in the column in 500-g fractions, leaving a final headspace of $20 \%$. After the introduction of each fraction, the soil was compacted in a way that guaranteed similar soil porosities in all studies. In the second stage, $1.0 \mathrm{~g}$ of EB was added on the top of the column. The initial concentration of EB in each experiment is presented in Table 1. The soil was then left isothermally at $23^{\circ} \mathrm{C}$. Toevaluate if equilibrium was reached, the concentration of the contaminant in the soil gas phase was monitored over time at four different heights of the column. The samples were collected at sampling ports located at the top of the column and at 5, 10 , and $15 \mathrm{~cm}$ above the base. When the concentrations at the four levels were similar (deviation $<5 \%$ ), equilibrium was considered to have been reached, which happened within $48 \mathrm{~h}$ in all cases. After the establishment of the equilibrium, the column was connected to the laboratorial installation to perform the SVE.

To start the SVE experiment, the vacuum pump was switched on, allowing a controlled (by a flow meter) airflow to pass through the column and then through a
Table 1 Results obtained in the SVE experiments
$A$ completely achieved, $N$ nearly achieved, $X$ not achieved

\begin{tabular}{|c|c|c|c|c|c|}
\hline Soil & $\begin{array}{l}\text { Initial concentration } \\
\text { of } \mathrm{EB}\left(\mathrm{mg} \mathrm{kg}^{-1}\right)\end{array}$ & $\begin{array}{l}\text { Flow rate } \\
\left(\mathrm{L} \mathrm{h}^{-1}\right)\end{array}$ & $\begin{array}{l}\text { Remediation } \\
\text { time (h) }\end{array}$ & $\begin{array}{l}\text { Concentration of } \\
\text { remaining } \\
\text { contamination } \\
\left(\mathrm{mg} \mathrm{kg}^{-1}\right)\end{array}$ & $\begin{array}{l}\text { Cleanup goal } \\
\text { achievement* }\end{array}$ \\
\hline \multirow[t]{4}{*}{$P_{0,0}$} & 250 & 18 & 3.0 & 14 & A \\
\hline & & 9.1 & 5.3 & 16 & A \\
\hline & & 5.0 & 6.8 & 22 & A \\
\hline & & 2.0 & 12.5 & 16 & A \\
\hline \multirow[t]{4}{*}{$\mathrm{P}_{2,0}$} & 250 & 18 & 3.9 & 22 & A \\
\hline & & 12 & 5.5 & 16 & A \\
\hline & & 4.1 & 11.6 & 21 & A \\
\hline & & 2.4 & 16.7 & 18 & A \\
\hline \multirow[t]{4}{*}{$\mathrm{P}_{3,0}$} & 250 & 18 & 4.6 & 6 & A \\
\hline & & 8.9 & 7.8 & 3 & A \\
\hline & & 6.5 & 11.6 & 3 & A \\
\hline & & 1.8 & 18.7 & 2 & A \\
\hline \multirow[t]{4}{*}{$\mathrm{P}_{4,0}$} & 250 & 17 & 4.0 & 6 & A \\
\hline & & 9.2 & 7.2 & 3 & A \\
\hline & & 3.5 & 13.1 & 2 & A \\
\hline & & 2.2 & 25.9 & 1 & A \\
\hline \multirow[t]{4}{*}{$P_{1,4}$} & 370 & 18 & 5.7 & 131 & $\mathrm{~N}$ \\
\hline & & 9.8 & 10.0 & 117 & $\mathrm{~N}$ \\
\hline & & 6.0 & 15.5 & 123 & $\mathrm{~N}$ \\
\hline & & 2.4 & 52.3 & 51 & A \\
\hline \multirow[t]{3}{*}{$P_{2,14}$} & 670 & 9.2 & 18.9 & 335 & $X$ \\
\hline & & 4.9 & 28.1 & 235 & $X$ \\
\hline & & 2.2 & 68.5 & 107 & $\mathrm{~N}$ \\
\hline \multirow[t]{4}{*}{$P_{4,24}$} & 1,110 & 18 & 7.0 & 744 & $X$ \\
\hline & & 8.2 & 21.5 & 591 & $X$ \\
\hline & & 5.7 & 23.4 & 438 & $X$ \\
\hline & & 2.2 & 69.8 & 154 & $X$ \\
\hline
\end{tabular}


sampling system where gas emissions were collected and monitored by gas chromatography. An activated charcoal recipient was placed before the pump for its protection and to avoid atmospheric contamination. The remediation process was considered finalized when the concentration of the contaminant in the gas phase was below $1.0 \mathrm{mg} \mathrm{L}^{-1}$ (Soares et al. 2010). The time needed to reach this level was considered the SVE remediation time, and the remaining concentration of EB in the soil was calculated.

\subsection{Bioremediation Experiments}

The BR experiments were preceded by degradation studies in order to evaluate the capacity of the soil microorganism (native or in consortium with other inoculated microbes) to biodegrade EB. These tests were conducted in Erlenmeyer flasks containing $30 \mathrm{~g}$ of a $\mathrm{P}_{2,14}$ soil (native or sterilized, with or without inoculated microorganisms), mineral nutrients (MinE, $10 \mathrm{~mL} \mathrm{~kg}_{\text {soi }} 1^{-1}$ ), water (to induce a SWC of 20\%), and EB (to induce a contamination of $100 \mathrm{mg} \mathrm{kg}_{\text {soil }}{ }^{-1}$ ). Theinoculated microorganisms were: Labrys portucalensis strain F11, Pseudomonas fluorescens strain PFST, Pseudomonas stutzeri strain OX1, and Pseudomonas putida strain KT2440. The cultures' growth was monitored by UV-Vis spectrometry, and they were used when the absorbance reached its maximum value (approximately 1.3). Based on these tests, the best consortium was identified and used in the BR experiments.

The BR experiments were only performed in the soils that after SVE presented contamination levels above the considered legal limits. In the preparation of the soils for BR, as performed in the degradation tests, water and substrate were added to the soil. No external oxygen supply was used during the process because there was enough air in the headspace of the columns. These experiments were considered finished when the concentration of EB in the soil reached the legal limit $\left(100 \mathrm{mg} \mathrm{kg}^{-1}\right)$. Columns were prepared with sterile $\mathrm{P}_{2,14}$ and $\mathrm{P}_{4,24}$ soils (sterilized by autoclaving at $120^{\circ}$ for $30 \mathrm{~min}$ ) contaminated with $100 \mathrm{mg} \mathrm{kg}^{-1}$ of EB. After the establishment of the equilibrium in the column, the concentration of EB in the gas phase of the soil was $5.0 \mathrm{mg} \mathrm{L}^{-1}$ for soil $\mathrm{P}_{2,14}$ and $3.7 \mathrm{mg} \mathrm{L}^{-1}$ for soil $\mathrm{P}_{4,24}$. The BR time was defined as the time required to reach these concentrations. The sum of the SVE remediation time and the BR time was defined as the global remediation time.

\section{Results}

\subsection{Soil Vapor Extraction Experiments}

At the end of each SVE, the remediation time and the remaining level of contamination in the soil were established (Table 1). The last column indicates the level of achievement of the cleanup goal. If the remaining concentration was below the legal limit (100 $\mathrm{mg} \mathrm{kg}^{-1}$ ), the goal was considered to be completely achieved. This situation is identified in Table 1 with an "A." If the level of contamination at the end of the SVE was within 100 and $150 \mathrm{mg} \mathrm{kg}^{-1}$, the cleanup goal was considered to be nearly achieved (indicated with an "N"). This means that the EB concentration is slightly higher than the legal limit, and that a further reduction of the concentration could probably be achieved by prolongation of the SVE. In the cases in which the final level of contamination was above $150 \mathrm{mg} \mathrm{kg}^{-1}$ (identified with an "X"), the remediation was considered incomplete and was complemented with BR to reach the final level of $100 \mathrm{mg} \mathrm{kg}^{-1}$.

The results presented in Table 1 show that in 63\% of the experiments, the cleanup goals were achieved solely with SVE, which demonstrates the efficiency of SVE for the considered soils, especially for sandy soils in which SVE managed to reach the legal limits in all the studies. In $15 \%$ of the cases, the cleanup goals were nearly achieved, and in $22 \%$, these were not achieved and required further bioremediation.

From the results presented in Table 1, it can be concluded that when sandy soils and higher airflow rates were used the soil water content had a low impact on the SVE process. However, for soils with higher SWCs and lower airflow rates longer remediations were observed. Soils with higher water contents have a lower capacity to adsorb EB, increasing the tendency of the contaminant to remain in the gas phase of the soil, thus becoming more mobile and easier to extract. This behavior is enhanced by the low water solubility of EB and could explain the low level of remaining contamination observed in soils $\mathrm{P}_{3,0}$ and $\mathrm{P}_{4,0}$.

In humic soils, slower and less efficient remediations were obtained. This effect was more evident in the soil with the highest $\operatorname{NOMC}\left(\mathrm{P}_{4,24}\right)$. This is due to the high amount of organic matter which increases to soil's capacity to adsorb higher amounts of contaminant, which subsequently reduces its mobility and capability to be extracted (Alvim-Ferraz et al. 2006). 
The impact of NOMC on the remediation time was even clearer when lower airflow rates were used, resulting in longer remediation times and in higher remaining levels, originating lower efficiencies, and in several cases, requiring $\mathrm{BR}$ to achieve the legal cleanup goals.

According to the presented results, SVE is extremely efficient for the remediation of soils contaminated with VOC, and especially EB. However, in soils with NOMC above $4 \%$, SVE is not sufficient to achieve the legal limits requiring other remediation actions. This information could be extremely important for remediation technicians during the project phase, where the choice of the most appropriate technology is made.

\subsection{Bioremediation Experiments}

The results of the initial biodegradation studies are presented in Fig. 1. Comparing the results obtained with the sterile soil and the other tests, it can be concluded that the reduction of the EB concentration in the gas phase was due to biological activity. The tests performed with the different consortia of microorganisms gave similar results showing similar capacities to degrade the EB present in the soil, and no significant increase in the degrading process was observed when external augmentation with specific bacterial strains was experimented. Following this, the utilization of the native microorganisms to perform the BR was chosen because it was the easiest method toimplement and avoided the introduction of exogenous strains to the soil. The presence of exogenous microorganisms can in some cases create predation by protists or the competition with autochthonous microorganisms for electron acceptors or nutrients creating a negative impact on the bioaugmentation process (Fantroussi and Agathos 2005).

As stated before, the BR experiments were performed in those cases in which the cleanup goals had not been achieved by SVE and therefore required further treatment. These were the $\mathrm{P}_{2,14}$ soil with remaining concentrations of EB of 235 and $335 \mathrm{mg} \mathrm{kg}^{-1}$ and the $\mathrm{P}_{4,24}$ soil with remaining concentrations of 154,438 , 591 , and $744 \mathrm{mg} \mathrm{kg}^{-1}$. The monitoring of the BR processes is presented in Fig. 2a, b, for soils $\mathrm{P}_{2,14}$ and $\mathrm{P}_{4,24}$, respectively.

Figure 2a shows that in the $\mathrm{P}_{2,14}$ soil, $\mathrm{BR}$ managed to achieve the defined cleanup goal for both EB concentrations. The monitoring curves for the two experiments are almost parallel, indicating similar degradation rates with two distinct stages. In the first stage, within the first $300 \mathrm{~h}$, in which, and because of the addition of water and substrate, pollutant diffusion/partition, possibly coupled with an initial slow microbial activity, originated a fast decrease of the EB concentration in the gas phase. The second stage was characterized by a continuous and consistent degradation of EB due to a stable microbial activity. In this stage, equilibrium has been reached, and the reduction of the concentration of the contaminant in the gas phase occurs in equilibrium conditions; therefore, the movement of contaminant in the soil matrix is not significant.
Fig. 1 Biodegradation tests (in Erlenmeyer flasks)

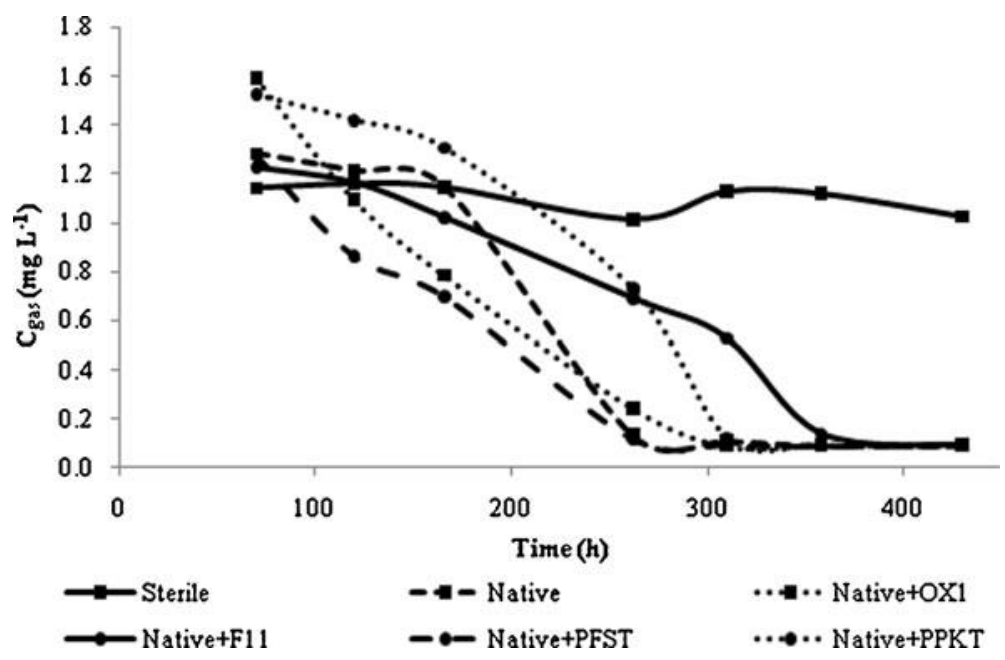


Fig. 2 a Bioremediation monitoring in $\mathrm{P}_{2,14}$ soil (in column). b Bioremediation monitoring in $\mathrm{P} 4,24$ soil (in column)
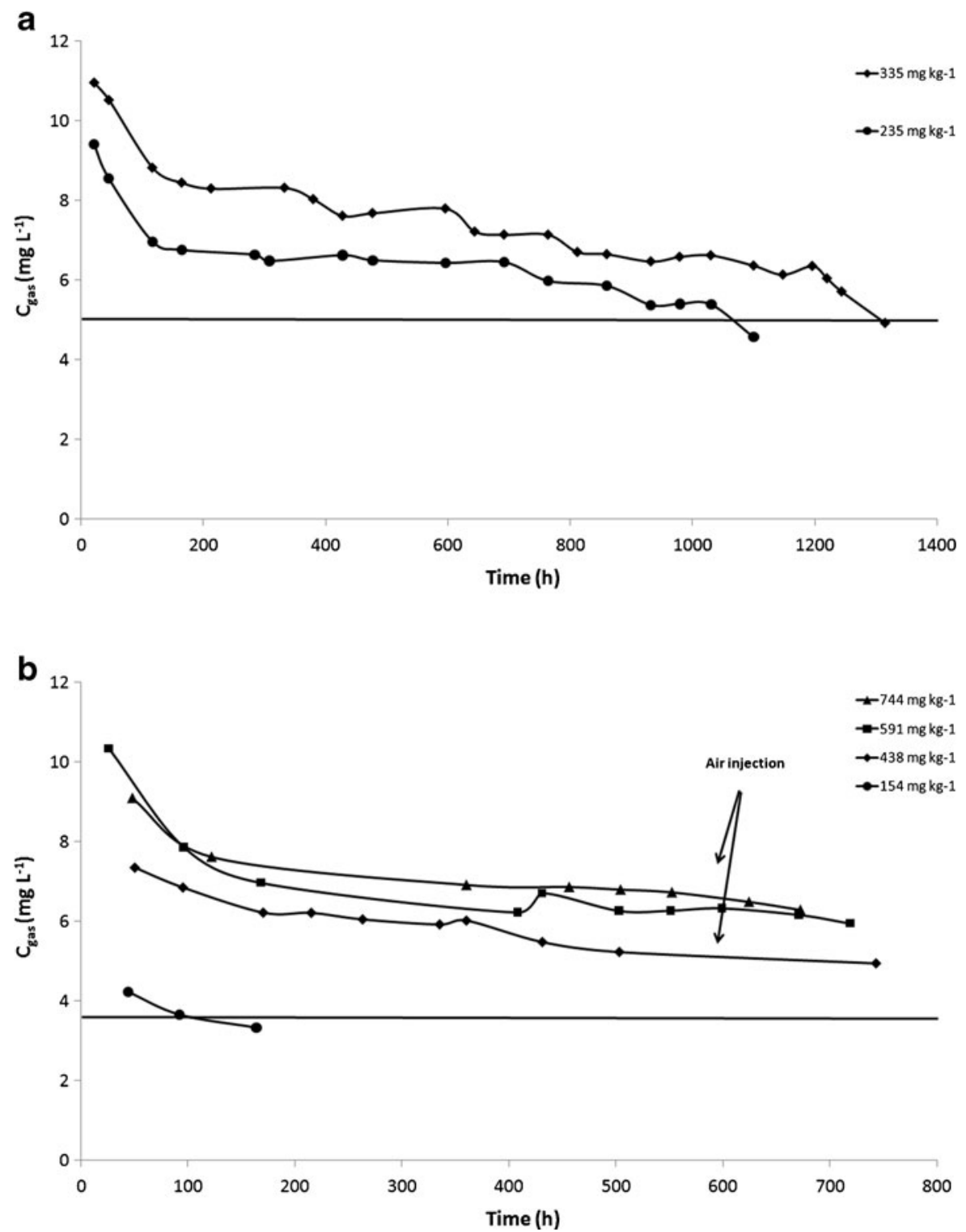

Figure $2 \mathrm{~b}$ presents different results. The experiment with the lowest level of contamination (154 $\mathrm{mg} \mathrm{kg}_{\text {soil }}{ }^{-1}$ ) easily and rapidly reached the legal limit, but in the other experiments, after an initial decrease of the EB concentration, probably due to the establishment of the distribution of EB in the soil phases, no significant degradation was observed. This seems to indicate that higher concentrations of EB affect microbial activity and inhibit the bioremediation process. To verify if this behavior was not due to the lack of oxygen in the soil matrix, air was injected $(10 \mathrm{~mL})$ at different levels of the soil column after $600 \mathrm{~h}$, but no improvement or changes were observed.
Table 2 Bioremediation and global remediation times

\begin{tabular}{llll}
\hline Soil & $\begin{array}{l}\text { Remaining } \\
\text { concentration } \\
\left(\mathrm{mg} \mathrm{kg}^{-1}\right)\end{array}$ & $\begin{array}{l}\text { Bioremediation } \\
\text { time }(\mathrm{h})\end{array}$ & $\begin{array}{l}\text { Global remediation } \\
\text { time }(\mathrm{h})\end{array}$ \\
\hline
\end{tabular}

\begin{tabular}{lrrr}
\hline $\mathrm{P}_{2,14}$ & 235 & 1,100 & 1,128 \\
& 335 & 1,315 & 1,334 \\
$\mathrm{P}_{4,24}$ & 154 & 164 & 234 \\
& 438 & $\mathrm{NA}$ & $\mathrm{NA}$ \\
& 591 & $\mathrm{NA}$ & $\mathrm{NA}$ \\
& 744 & $\mathrm{NA}$ & $\mathrm{NA}$ \\
\hline
\end{tabular}

NA legal limit not achieved 
At the end of the BR experiments, the BR- and global remediation times were calculated (Table 2). The results show that the utilization of BR to complement SVE can be adequate to reach the cleanup goals when the remaining levels after SVE are below $335 \mathrm{mg} \mathrm{kg}_{\text {soil }}{ }^{-1}$. Above this value, inhibitory effects on the degradation process may occur making the remediation unfeasible with the proposed methodologies. Furthermore, BR could be inadequate if a fast remediation is required because BR is responsible for $70 \%$ to $98.5 \%$ of the global remediation time.

In a previous study (Soares et al. 2010), the remediation of benzene-contaminated soils using the sequential application of SVE and BR was studied. It was concluded that the remediation times were directly proportional to the level of contamination and inversely proportional to NOMC, showing that organic matter hinders SVE but enhances BR. This was explained by the fact that soils with higher NOMCs may contain more indigenous microorganisms, increasing the biodegradation of the contaminant. In comparison with this study, the BR times for benzene (lower than $650 \mathrm{~h}$ ) were lower than the BR times for EB $(1,100-1,300 \mathrm{~h})$ and the degradation rates for EB (4.4 to $9.5 \mathrm{mg} \mathrm{d}^{-1}$ ) were lower than the degradation rates for benzene (5.0 to $18 \mathrm{mg} \mathrm{d^{-1 }}$ ).

\section{Conclusions}

The remediation experiments performed in soils contaminated with EB led to the following conclusions:

- SVE reached the cleanup goals in $63 \%$ of the experiments;

- SVE performed in sandy soils with high SWCs and using lower airflow rates required considerably longer remediation times;

- In humic soils, longer and less efficient SVE processes were observed;

- EB concentrations above $438 \mathrm{mg} \mathrm{kg}_{\text {soil }}{ }^{-1}$ showed to be inhibitory to microbial activity;

In summary, this work shows the limitations of SVE and in what conditions they occur and demonstrate that $\mathrm{BR}$ can be an easy and adequate option to complement SVE in order to achieve the cleanup goals. Despite the considerable increase of the remediation time, BR offers the advantage of being an inexpensive process assuming that there is no need for fast treatment.
Acknowledgments The authors are grateful to the "Fundação para a Ciência e a Tecnologia (FCT)" for the financial support for this work (PTDC/ECM/68056/2006).

\section{References}

Albergaria, J. T., Delerue-Matos, C., \& Alvim-Ferraz, M. C. M. (2006). Remediation efficiency of vapour extraction of sandy soils contaminated with cyclohexane: Influence of air flow rate and of water and natural organic matter contents. Environmental Pollution, 143(1), 146-152.

Alvim-Ferraz, M. C. M., Albergaria, J. T., \& Delerue-Matos, C. (2006). Soil remediation time to achieve clean-up goals: II: Influence of natural organic matter and water contents. Chemosphere, 64, 817-825.

ATSDR, Agency for Toxic Substances and Disease Registry. (1999). Toxicological profile for ethylbenzene (update). Atlanta: Public Health Service, U.S. Department of Health and Human Services.

Corseuil, H. X., \& Weber, W. J. (1994). Potential biomass limitations on rates of degradation of monoaromatic hydrocarbons by indigenous microbes in subsurface soils. Water Resources Research, 28, 1415-1423.

Fantroussi, S., \& Agathos, S. N. (2005). Is bioaugmentation a feasible strategy for pollutant removal and site remediation? Current Opinion in Microbiology, 8(3), 268-275.

Grasso, D. (1993). Hazardous waste site remediation, source control. Connecticut: Lewis Publisher Inc.

Harper, B. M., Stiver, W. H., \& Zytner, R. G. (1998). Influence of water content on SVE in a silt loam soil. Journal of Environmental Engineering and Science, 124, 1047-1053.

Jean, J. S., Lee, M. K., Wang, S. M., Chattopadhyay, P., \& Maity, J. P. (2008). Effects of inorganic nutrient levels on the biodegradation of benzene, toluene, and xylene (BTX) by Pseudomonas spp. in a laboratory porous media sand aquifer model. Bioresource Technology, 99, 7807-7815.

Kelly, D. P., Baker, S. C., Trickett, J., Davey, M., \& Murrell, J. C. (1994). Methanesulphonate utilization by a novel methylotrophic bacterium involves an unusual monooxygenase. 1Microbiology, 140, 1419-1426.

Lewis, D. L., Kollig, H. P., \& Hodson, R. E. (1986). Nutrient limitation and adaptation of microbial populations to chemical transformations. Applied and Environmental Microbiology, 51, 598-603.

Poulsen, T. G., Moldrup, P., Yamaguchi, T., Schjonning, P., \& Hansen, J. A. (1999). Predicting soil-water and soil-air transport properties and their effects on soil-vapor extraction efficiency. Ground Water Monitoring and Remediation, 19, 61-70.

Qin, C., Zhao, Y., Zheng, W., \& Li, Y. (2010). Study on influencing factors on removal of chlorobenzene from unsaturated zone by soil vapor extraction. Journal of Hazardous Materials, 176(1-3), 294-299.

Romantshuck, M. (2000). Bioremediation of contaminated soil and groundwater. Environmental Pollution, 107, 179-185. Sepehr, M., \& Samani, Z. A. (1993). In situ soil remediation using vapor extraction wells, development and testing of a 
3-dimensional finite-difference model. Ground Water, 31, 425-436.

Soares, A. A., Albergaria, J. T., Domingues, V.F., Alvim-Ferraz, M. C. M., \& Delerue-Matos, C. (2010). Remediation of soils combining soil vapor extraction and bioremediation: Benzene. Chemosphere, 80,823-828.

Sun, H., Tateda, M., Ike, M., et al. (2003). Short- and long-term sorption/desorption of polycyclic aromatic hydrocarbons onto artificial solids: Effects of particle and pore sizes and organic matters. Water Resources Research, 37, 2960-2968.

Suthersan, S. S. (1999). Soil vapour extraction. In Remediation engineering: Design concepts (pp. 27-88). Boca Raton: Lewis Publisher Inc.
Thomassin-Lacroix, E. J. M. (2000). Fate and effects of hydrocarbon-degrading bacterial used to inoculate soil for on-site bioremediation in the Arctic. M.S. Thesis, Royal Military College of Canada.

Tyagi, M., Fonseca, M. M. R., \& Carvalho, C. C. C. R. (2011). Bioaugmentation and biostimulation strategies to improve the effectiveness of bioremediation processes. Biodegradation, 22, 231-241.

USEPA, United States Environmental Protection Agengy (2010). Superfund Remedy Report, 13th Ed.. Resource document. http://www.clu-in.org/asr/. Accessed 5 Mar 2010.

Yang, S. Z., Jin, H. J., Wei, Z., He, R. X., Ji, Y. J., Li, X. M., et al. (2009). Bioremediation of oil spills in cold environments: A review. Pedosphere, 19(3),371-381. 